\title{
АНАЛИЗ СТОИМОСТИ СЕЛЬХОЗЗЕМЕЛЬ В НОВОСИБИРСКОЙ ОБЛАСТИ
}

\section{Денис Вадимович Арутюнов}

Сибирский государственный университет геосистем и технологий, 630108, Россия, г. Новосибирск, ул. Плахотного, 10, обучающийся, тел. (953)768-74-10, e-mail: qwerty02059682@gmail.com

В статье отражена важность и актуальность сельскохозяйственных земель. Рассмотрен общий земельный фонд Новосибирской области. Дана краткая характеристика и статистические данные по основным категориям земель. Проанализирована кадастровая стоимость сельскохозяйственных угодий Новосибирской области за 2020 год. На основе данных, приведенных в таблицах, отражена средняя стоимость, max и min, по районам Новосибирской области, входящих в сельскохозяйственные группы. Подведены итоги анализа сельскохозяйственных земель Новосибирской области.

Ключевые слова: сельскохозяйственное угодье, рынок земель, рыночная стоимость земли, рациональное использование земли, земельный участок, анализ стоимости земли, ценность земли, мониторинг земель

\section{ANALYSIS OF THE COST OF AGRICULTURAL LANDS IN THE NOVOSIBIRSK REGION}

\section{Denis V. Arutyunov}

Siberian State University of Geosystems and Technologies, 10, Plakhotnogo St., Novosibirsk, 630108, Russia, Student, phone: (953) 768-74-10, e-mail: qwerty02059682@gmail.com

The article reflects the importance and relevance of agricultural land. The general land fund of the Novosibirsk region is considered. A brief description and statistical data on the main categories of land are given. The cadastral value of agricultural land in the Novosibirsk region for 2020 is analyzed. Based on the data given in the tables, the average cost, max and min, for the districts of the Novosibirsk region included in agricultural groups is reflected. The results of the analysis of agricultural lands of the Novosibirsk region are summed up.

Keywords: agricultural land, land market, market value of land, rational use of land, land plot, land value analysis, land value, land monitoring

\section{Введение}

Невозможно представить деятельность общественности без использования земли. Земля является природным ресурсом, благом, которое обладает высокой ценностью и стоимостью.

Земля как объект недвижимости представляет собой территорию с определенными границами. Она может использоваться с целью получения дохода [2].

Сельскохозяйственные угодья сегодня в большей степени выступают, как объекты товарно-хозяйственных отношений. Анализ стоимости сельхоз земель на рынке Новосибирской области является актуальной темой [7].

Это обусловлено тем, что земля введена в гражданский оборот, то есть общество может приобретать земельные участки под частную собственность [3]. 
Поэтому необходимо регулировать и контролировать рынок цен на земельные участки.

Цель исследования - проведение анализа кадастровой стоимости сельскохозяйственных угодий Новосибирской области.

Объектом исследования выступают земельные участки сельскохозяйственного назначения Новосибирской области.

\section{Эксперименты}

Информационной базой исследования выступили сведения департамента имущества и земельных отношений Новосибирской области.

Все земли Новосибирской области являются земельным фондом.

Площадь земельного фонда Новосибирской области составляет 17775,6 тыс.га [1].

По целевому назначению земли подразделяют на семь основных категорий (рис.1).

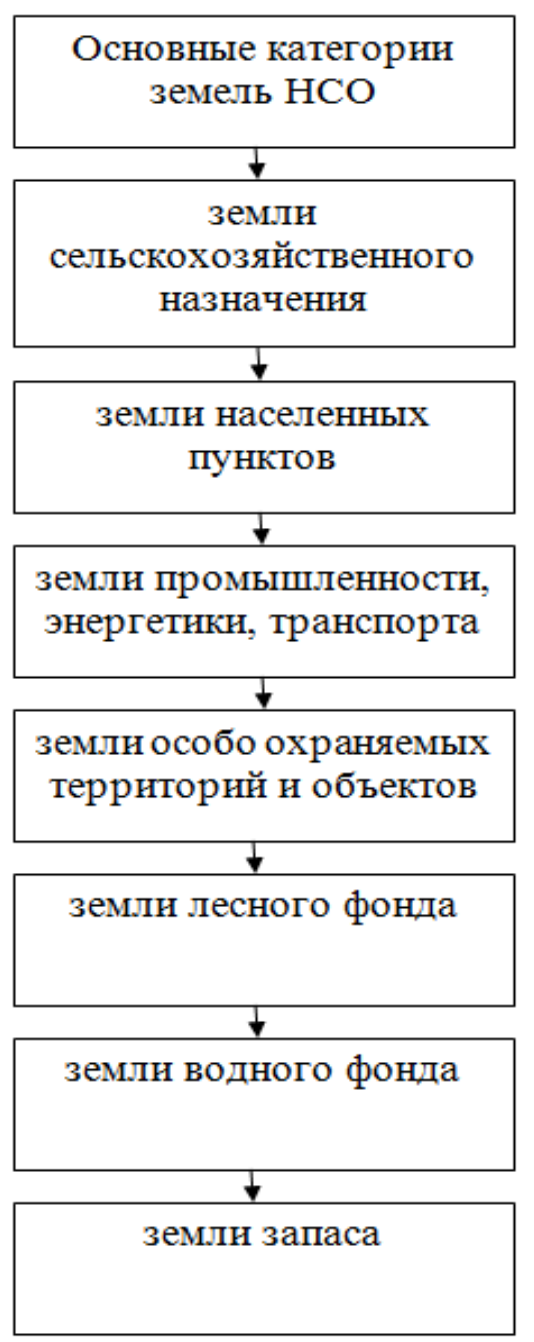

Рис. 1. Основные категории земель НСО 
Оценке кадастровой стоимости подлежат следующие объекты (рис.2).

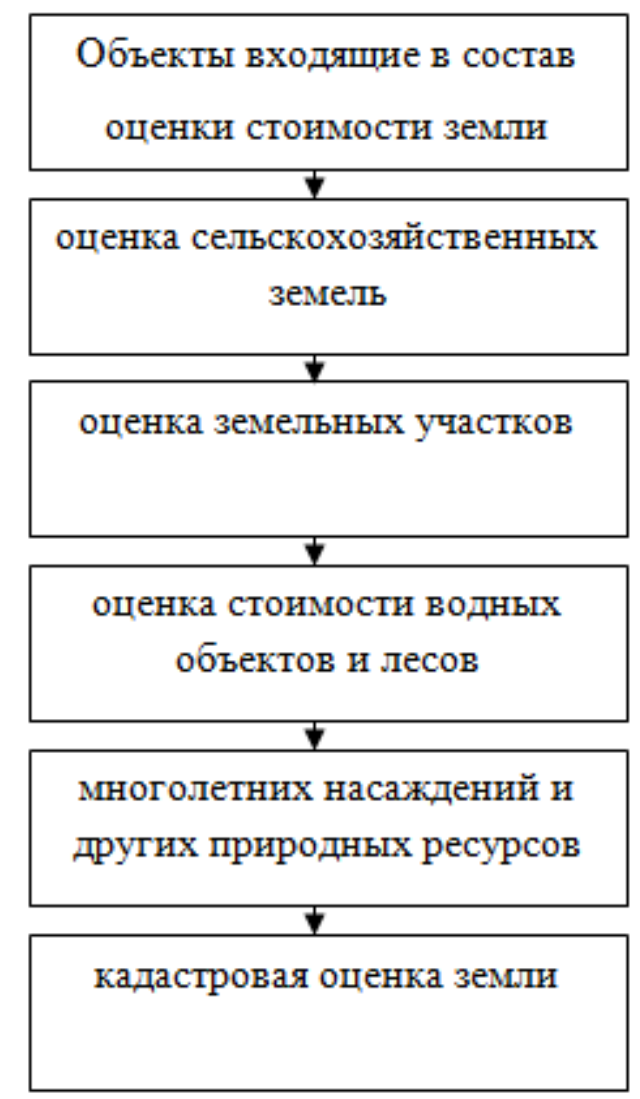

Рис. 2. Объекты, подлежащие оценке их стоимости

В табл. 1 приведены актуальные сведения о площади категорий земельного фонда в Новосибирской области. Как видно из таблицы, более 60 \% от общего фонда региона занимают земли сельскохозяйственного назначения [8].

\section{Таблииа 1}

Категории земель и их площадь от общей площади Новосибирской области

\begin{tabular}{|c|c|c|}
\hline Категории земель & Площадь земель в $\%$ & Площадь в тыс.га. \\
\hline Сельскохозяйственные земли & 62,5 & 11128,5 \\
\hline Земли лесного фонда & 25,5 & 4615,2 \\
\hline Земли запаса & 6,2 & 1041,2 \\
\hline Земли водного фонда & 3,1 & 595 \\
\hline $\begin{array}{c}\text { Земли под строительство } \\
\text { жилых комплексов }\end{array}$ & 1,4 & 267,4 \\
\hline $\begin{array}{c}\text { Земли для предприниматель- } \\
\text { ской деятельности }\end{array}$ & 0,9 & 125,6 \\
\hline $\begin{array}{c}\text { Фонд земель особо охраняе- } \\
\text { мых }\end{array}$ & 0,4 & 2,7 \\
\hline Всего & 100 & 17775,6 \\
\hline
\end{tabular}


Ежегодно происходит уменьшение площади земель сельскохозяйственного назначения. На рис. 3 представлена информация о сокращении земель сельскохозяйственного назначения на 2017-2020 год[9].

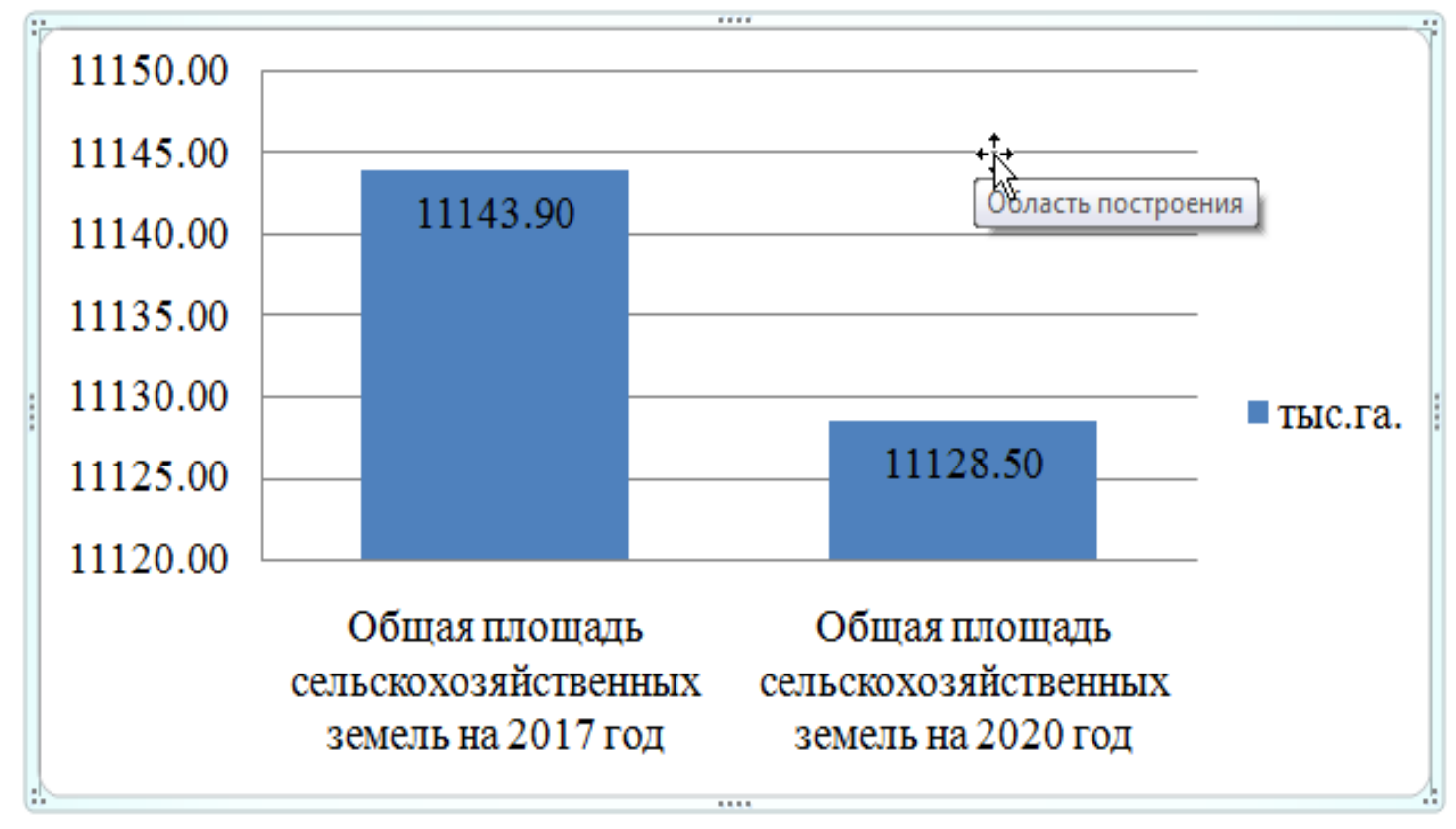

Рис. 3. Сокращение сельскохозяйственных земель на 2017-2020 год

На рис. 2 представлена информация о сокращении сельскохозяйственных земель Новосибирской области. Видно, что общее количество сельскохозяйственных земель Новосибирской области за 3 года сократилось на 15,4 тыс.га. Данное сокращение обусловлено переводом участков из одной категории в другую [1].

Анализ стоимости сельскохозяйственных земель в Новосибирской области за 2020 год был взят из приказа департамента имущества и земельных отношений от 01.09.2020 № 2564 (табл. 2).

Таблица 2

Средний уровень кадастровой стоимости сельскохозяйственных земель в Новосибирской области за 2020 год

\begin{tabular}{|c|c|c|c|c|c|c|c|}
\hline \multirow{2}{*}{$\begin{array}{c}\text { № } \\
\text { п/П }\end{array}$} & $\begin{array}{c}\text { Наименование муниципального } \\
\text { района (городского округа) }\end{array}$ & \multicolumn{6}{|c|}{$\begin{array}{l}\text { Удельные показатели кадастровой стоимости } \\
\text { земель сельскохозяйственного назначения по } \\
\text { группам, руб./кв.м }\end{array}$} \\
\cline { 3 - 8 } & & 1 & 2 & 3 & 4 & 5 & 6 \\
\hline 1 & Баганский район & 0,21 & - & - & - & 0,10 & 0,25 \\
\hline 2 & Барабинский район & - & - & - & - & 0,03 & 0,59 \\
\hline 3 & Болотнинский район & 0,65 & - & - & - & 0,06 & 1,36 \\
\hline
\end{tabular}


Окончание табл. 2

\begin{tabular}{|c|c|c|c|c|c|c|c|}
\hline \multirow[t]{2}{*}{$\begin{array}{c}\text { № } \\
\Pi / \Pi\end{array}$} & \multirow[t]{2}{*}{$\begin{array}{c}\text { Наименование муниципального } \\
\text { района (городского округа) }\end{array}$} & \multicolumn{6}{|c|}{$\begin{array}{c}\text { Удельные показатели кадастровой стоимости } \\
\text { земель сельскохозяйственного назначения по } \\
\text { группам, руб./кв.м }\end{array}$} \\
\hline & & 1 & 2 & 3 & 4 & 5 & 6 \\
\hline 4 & Венгеровский район & - & 311,25 & - & 101,70 & 0,01 & 1,60 \\
\hline 5 & Доволенский район & - & - & - & - & 0,01 & - \\
\hline 6 & Здвинский район & - & - & - & - & 0,13 & 1,11 \\
\hline 7 & Искитимский район & - & 257,90 & 160,04 & 2,56 & 0,03 & 1,87 \\
\hline 8 & Карасукский район & - & - & - & - & 0,21 & 0,25 \\
\hline 9 & Каргатский район & - & - & - & - & 0,003 & 0,93 \\
\hline 10 & Колыванский район & 7,19 & - & 80,45 & - & 0,003 & 1,19 \\
\hline 11 & Коченевский район & 0,86 & - & 120,85 & - & 0,01 & 0,66 \\
\hline 12 & Кочковский район & 0,29 & - & - & - & 0,07 & 1,69 \\
\hline 13 & Краснозерский район & - & - & - & - & 0,01 & 0,72 \\
\hline 14 & Куйбышевский район & - & - & - & - & 0,07 & 1,16 \\
\hline 15 & Купинский район & - & - & - & - & 0,02 & 1,05 \\
\hline 16 & Кыштовский район & 0,45 & - & - & - & 0,01 & 0,61 \\
\hline 17 & Маслянинский район & 1,36 & - & 107,69 & 2,14 & 0,03 & 3,10 \\
\hline 18 & Мошковский район & - & 2,90 & - & - & 0,59 & 2,22 \\
\hline 19 & Новосибирский район & - & - & 145,19 & 6,24 & 0,08 & 2,03 \\
\hline 20 & Ордынский район & - & 146,71 & 160,60 & 9,93 & 0,03 & 0,83 \\
\hline 21 & Северный район & - & - & - & 0,19 & 0,01 & 0,89 \\
\hline 22 & Сузунский район & - & - & - & 8,99 & 0,02 & 1,83 \\
\hline 23 & Татарский район & - & - & - & - & 0,01 & 0,82 \\
\hline 24 & Тогучинский район & 8,57 & - & 120,85 & 3,20 & 0,03 & 1,75 \\
\hline 25 & Убинский район & - & - & - & - & 0,02 & 0,89 \\
\hline 26 & Усть-Таркский район & - & - & - & - & 0,02 & 1,06 \\
\hline 27 & Чановский район & - & - & - & - & 0,13 & 1,32 \\
\hline 28 & Черепановский район & - & - & - & - & - & 2,28 \\
\hline 29 & Чистоозерный район & 0,54 & - & - & - & 0,08 & 1,05 \\
\hline 30 & Чулымский район & - & - & - & - & 0,02 & 0,24 \\
\hline 31 & Среднее по Новосибирской области & 20,12 & 718,76 & 895,67 & 134,95 & 1,85 & 35,35 \\
\hline
\end{tabular}

В табл. 2 представлены показатели стоимости сельскохозяйственных земель, Новосибирской области. Видно, что в состав сельскохозяйственных земель входит 31 район. Каждый район имеет свою индивидуальную стоимость за кв.м, которая формируется в зависимости от того, к какой группе район относится [5]. Всего выделяют 6 основных групп сельскохозяйственного назначения (табл. 3). 
Основные группы сельскохозяйственного назначения

\begin{tabular}{|c|c|c|}
\hline № группы & Название группы & $\begin{array}{c}\text { Средняя кадастровая стои- } \\
\text { мость, руб./кв.м }\end{array}$ \\
\hline 1 & земли пригодные под пашни & 20,12 \\
\hline 2 & $\begin{array}{l}\text { земли используемые для вы- } \\
\text { ращивания }\end{array}$ & 718,76 \\
\hline 3 & $\begin{array}{c}\text { земли занятые зданиями, } \\
\text { строениями }\end{array}$ & 895,67 \\
\hline 4 & $\begin{array}{c}\text { земли занятые водными объ- } \\
\text { ектами }\end{array}$ & 134,95 \\
\hline 5 & $\begin{array}{l}\text { земли на которых располага- } \\
\text { ются леса }\end{array}$ & 1,85 \\
\hline 6 & $\begin{array}{c}\text { Прочие земли (болота, овра- } \\
\text { ги, полигоны) }\end{array}$ & 35,35 \\
\hline
\end{tabular}

В табл. 3 представлены основные группы земель сельскохозяйственного назначения, а также их средний коэффициент кадастровой стоимости. Видно, что каждая группа имеет свою определенную ценность, которая обусловлена геологическими, климатическими, региональными, социальными и экономическими факторами [10].

\section{Заключение}

Анализ кадастровой стоимости земельных участков в составе земель сельскохозяйственного назначения Новосибирской области представлен в табл. 2 [10].

Средний коэффициент кадастровой стоимости сельскохозяйственной земли на 2020 год в Новосибирской области за кв.м равен 301.1 руб.

Максимальный коэффициент кадастровой стоимости сельскохозяйственных земель Новосибирской области равен 895.67 руб. за кв.м. К этим землям относятся районы из 3 группы, то есть земли которые используются под строительство зданий и строений.

Минимальный коэффициент кадастровой стоимости сельскохозяйственной земли Новосибирской области за кв.м равен 1.85 руб. К этим землям относятся районы из 5 группы, то есть земли,на которых располагаются леса.

\section{БИБЛИОГРАФИЧЕСКИЙ СПИСОК}

1. Доклад о состоянии и использовании земель Новосибирской области в 2017 году. URL: www.to54.rosreestr.ru (дата обращения: 23.10.2020).

2. Кресникова Н.И. Земельный рынок России: институциональные аспекты // Аграрная Россия. 2016. № 1. С. 26-28.

3. Сучков А.И, Репотецкая М.Ю, Рыхта П.А. Анализ современного состояния и использования земель сельскохозяйственного назначения в Новосибирской области // Вестник Новосибирского государственного аграрного университета. 2016. № 3 (32). С. 125-130.

4. Методические рекомендации по определению рыночной стоимости земельных участков от 06.03.2016 № 568-p. URL: http://www.consultant.ru/document/cons_doc_LAW_38786/ (дата обращения: 23.10.2020). 
5. Приказ департамента имущества и земельных отношений Новосибирской области №2545 от 26.11.2015 URL:http://dizo.nso.ru/page/53 (дата обращения 23.10.2020).

6. Анцырев Ю.Ю., Хуажева А.Ш. Основные теоретико-методологические вопросы оценки земель сельскохозяйственного назначения // Вестник Адыгейского государственного университета. 2016. № 4. С. 62-65.

7. Буздалов И. Земельная реформа: взгляд сквозь призму замысла // Вопросы экономики. 2018. № 10. С. 126-138.

8. Оганесян Л.О., Федюнина Е.Н. Концептуальные подходы к исследованию функционирования рынка сельскохозяйственных земель // Известия Волгоградского государственного технического университета. 2017. Т. 20, № 17 (144). С. 100-106.

9. Шагайда Н.И. Формирование рынка земель сельскохозяйственного назначения в России // Отечественные записки. 2016. № 1. С. 262-268.

10. Репотецкая М.Ю. Анализ земельного рынка в Новосибирской области // Научная дискуссия: вопросы экономики и управления: сб. ст. XXXI Междунар. заоч. науч.-практ. конф. М., 2016. С. 71-74.

11. Павлова В.А. Современные формы организации кадастровой деятельности в России//Имущественные отношения в Российской Федерации. -2015. -№ 1. -С. 38-42.

12. Павлова В.А. Формирование стоимости земельного участка в системе управления земельными ресурсами//Землеустройство, кадастр и мониторинг земель. -2018. -№ 8. C. 32-35.

13. Уварова Е.Л. Зонирование как метод территориального планирования//Известия Санкт-Петербургского государственного аграрного университета. -2016. -№ 44. -С. 230-235.

14. Гарманов В.В., Павлова В.А. Экономика недвижимости с основами оценки: Уч.метод. пособие для студентов, обучающихся по направлению подготовки 21.03.02 «Землеустройство и кадастры» (уровень бакалавриата). -СПб.: СПбГАУ, 2017. -163с.

15. Livestock Diseases: Prevention, Control and Compensation Schemes. 2017. URL: http://www.oecd.org/countries/botswana/livestockdiseasespreventioncontrolandcompensationschemes.htm.

16. Managing Risk in Agriculture: Policy Assessment and Design. 2015.: OECD (2015). Managing Risk in Agricultura: Policy Assessment and besigh OECD Publishing. URL: http: // DOI: 10.1787/9789264116146-en.

17. OECD Fruit and Vegetables Scheme.Guidelines on Objective Tests. 2019. URL: http:// www.oecd.org/tad/standardsforseedstractorsforestfruitandvegetables/47288602.pdf.

18. OECD Seed Schemas.A Synthesis of International Regulatory.Aspects that Affect Seed Trade.2012. URLhttp://www.oecd.org/tad/standardsforseedstractorsforestfruitandvegetables/intern ationalregulatoryaspectsseedtrade.pdf.

19. OECD Scheme for the Certification of Forest Reproductive Material Moving in International Trade.Strategic Plan for the OECD Forest Seed and Plant Scheme.2010. URL: http://www.oecd.org/fr/tad/normespourlessemencestracteursmaterielforestierfruitsetlegumes /46092739.pdf.

20. Arefiev N., Garmanov V., Bogdanov V., Ryabov Yu., Terleev V., Badenko V. A market approach to the evaluation of the ecological-economic damage dealt to the urban lands (Рыночный подход к оценке эколого-экономического ущерба, нанесенного городской земли)//Procedia Engineering. -2015. -T. 117.-C. 26-31.

(С) Д. В. Арутюнов, 2021 